\title{
Reproductive Counseling by Clinic Healthcare Workers in Durban, South Africa: Perspectives from HIV-Infected Men and Women Reporting Serodiscordant Partners
}

\author{
L. T. Matthews, ${ }^{1,2,3}$ T. Crankshaw, ${ }^{4}$ J. Giddy, ${ }^{4}$ A. Kaida, ${ }^{5}$ C. Psaros, ${ }^{6}$ N. C. Ware, ${ }^{7}$ \\ J. A. Smit, ${ }^{8}$ and D. R. Bangsberg ${ }^{1,2}$ \\ ${ }^{1}$ Division of Infectious Disease and Center for Global Health, Massachusetts General Hospital, Boston, MA 02114, USA \\ ${ }^{2}$ Harvard Medical School, Boston, MA 02115, USA \\ ${ }^{3}$ Division of Infectious Disease, Beth Israel Deaconess Medical Center, Boston, MA 02115, USA \\ ${ }^{4}$ McCord Hospital, PMTCT Programme, Durban 4001, South Africa \\ ${ }^{5}$ Faculty of Arts and Sciences, Simon Fraser University, Vancouver, BC, Canada V6B 5K3 \\ ${ }^{6}$ Department of Psychiatry, Massachusetts General Hospital, Boston, MA 02114, USA \\ ${ }^{7}$ Department of Global Health and Social Medicine, Harvard Medical School, Boston, MA 02115, USA \\ ${ }^{8}$ Maternal, Adolescent, Child Health Division, University of the Witwatersrand, Durban 4110, South Africa \\ Correspondence should be addressed to L. T. Matthews, ltmatthe@bidmc.harvard.edu
}

Received 30 January 2012; Accepted 15 June 2012

Academic Editor: Jean R. Anderson

Copyright $\odot 2012$ L. T. Matthews et al. This is an open access article distributed under the Creative Commons Attribution License, which permits unrestricted use, distribution, and reproduction in any medium, provided the original work is properly cited.

Background. Understanding HIV-infected patient experiences and perceptions of reproductive counseling in the health care context is critical to inform design of effective pharmaco-behavioral interventions that minimize periconception HIV risk and support HIV-affected couples to realize their fertility goals. Methods. We conducted semistructured, in-depth interviews with 30 HIVinfected women (with pregnancy in prior year) and $20 \mathrm{HIV}$-infected men, all reporting serodiscordant partners and accessing care in Durban, South Africa. We investigated patient-reported experiences with safer conception counseling from health care workers (HCWs). Interview transcripts were reviewed and coded using content analysis for conceptual categories and emergent themes. Results. The study findings indicate that HIV-infected patients recognize HCWs as a resource for periconception-related information and are receptive to speaking to a HCW prior to becoming pregnant, but seldom seek or receive conception advice in the clinic setting. HIV nondisclosure and unplanned pregnancy are important intervening factors. When advice is shared, patients reported receiving a range of information. Male participants showed particular interest in accessing safer conception information. Conclusions. HIV-infected men and women with serodiscordant partners are receptive to the idea of safer conception counseling. HCWs need to be supported to routinely initiate accurate safer conception counseling with HIV-infected patients of reproductive age.

\section{Introduction}

Current HIV prevention strategies (condoms and abstinence) force HIV-serodiscordant couples to choose between risking HIV transmission to a partner, or accepting childlessness [1-12]. Behavioral strategies (home artificial insemination, sex without condoms limited to peak fertility), male circumcision [13-15], antiretroviral therapy (ART) for the infected partner [16-18], and preexposure antiretroviral prophylaxis (PrEP) for the negative partner [19-22] create opportunities for HIV-serodiscordant couples to realize fertility goals and minimize periconception HIV transmission [23-27]. Prior to effective HIV treatment, the prevailing professional recommendation was for people living with HIV to avoid having children $[28,29]$. In 2001, the U.S. Centers for Disease Control recommended that healthcare providers support the fertility desires of people living with HIV [30]. South Africa's constitution protects the right 
to reproductive choice for HIV-infected persons, and the most recent guidelines from the Southern African HIV Clinicians Society offer risk-reduction strategies for HIVserodiscordant couples who choose to conceive $[31,32]$.

Cross-sectional studies indicate that people living with HIV are receptive to safer conception advice from providers [33-36], but that healthcare workers (HCWs) are not routinely engaging in conversations about fertility desires or plans, a crucial first piece of any reproductive health intervention $[31,34,35,37]$. In Cape Town, over $30 \%$ of HIVinfected women and $65 \%$ of HIV-infected men attending public sector clinics were interested in having additional children, yet only $19 \%$ and $6 \%$, respectively, had discussed this with a HCW [38]. Among HIV-infected women in Johannesburg, with plans to conceive in the next year, $40 \%$ had ever had a conversation about fertility plans with a provider [34]. Conversations with HCWs about conception plans were also infrequent in Argentina [37], Brazil [39], and the United States [35]. Barriers to these conversations include a combination of patient (e.g., fear of judgment, lack of pregnancy planning), provider (e.g., limited experience, knowledge, or skills), and structural factors (e.g., competing healthcare demands, limited resources, poor integration of family planning and HIV services) [31, 35-37, 40, 41]. While some conversations may be initiated with HIV lay counselors, they may not have the skills to address clinical issues beyond their focused training $[42,43]$.

Data demonstrating that ARVs minimize HIV transmission suggest that periconception risk-reduction interventions will require HCW involvement [16, 19-22, 27]. In our conceptual framework for periconception risk behavior, HCWs have the potential to minimize risk behavior through providing information about HIV risk, offering prevention strategies, and promoting adherence to risk reduction strategies [44]. There are no data on practices in KwaZulu-Natal, the most HIV-affected province in South Africa, where $41 \%$ of pregnant women attending antenatal clinics are HIV positive [45]. A better understanding of current HCW knowledge, attitudes, and practices will enhance the provision of reproductive counseling for HIVinfected individuals by allowing for development of interventions that capitalize on HCW strengths and address weaknesses.

We present qualitative data resulting from interviews with 30 HIV-infected women and 20 HIV-infected men with serodiscordant sexual partners in Durban, South Africa. We previously reported on periconception risk behavior within this sample [33] and here focus on participant reports of their experiences with HCW provision of reproductive counseling. These data offer early insight into current HCW practices and may contribute to development of feasible safer conception interventions.

\section{Methods}

2.1. Study Setting, Patient Selection, Inclusion and Exclusion Criteria. Participants were recruited from the antiretroviral (ARV) and preventing maternal-to-child-transmission
(PMTCT) clinics within a state-aided (public/private partnership) general hospital serving a predominantly urban population from the greater Durban area where district antenatal clinic HIV prevalence is estimated at $41.5 \%$ [45]. In 2011, the ARV clinic was providing care and treatment to 4734 patients on ART. Sixty percent of these patients are women; the majority ( $>90 \%)$ are black South Africans. Patients pay approximately 25 USD per month for comprehensive HIV services, which includes the cost of ARVs. Pregnant patients pay approximately 35 USD per visit to access antenatal care, which includes PMTCT clinic services. In 2010, 200 HIV-infected pregnant women enrolled in this program.

Male participants were recruited from the ARV clinic and female participants were recruited from the ARV and PMTCT clinics. Inclusion criteria were (1) age 18-45 years; (2) HIV-positive; (3) pregnancy in the prior 12 months, including currently pregnant (for women); (4) partner of unknown or seronegative HIV status (prior to referent pregnancy) by participant report (father of the referent pregnancy for women, current sexual partner for men); (5) fluent in English or isiZulu; (6) able to give informed consent. Initial attempts to recruit men with partner pregnancy in the past year were unsuccessful, men were subsequently recruited independent of recent partner pregnancy. It is not clear if initial recruitment challenges were due to sensitivities of reporting partner pregnancy (in a setting where condoms are promoted strongly) or a paucity of men with recent partner pregnancy.

2.2. Procedures. We conducted in-depth, qualitative, individual interviews to explore reproductive decision-making, sexual transmission risk understanding and practices, and periconception risk understanding and practices [33]. Here, we focus on data from the questions "What have health care workers advised you about having children (after knowing your status)?" and "What advice have you received around getting pregnant/having children safely (since knowing your status)?"

Participants were recruited from March through July 2010 via purposive sampling from patients awaiting clinical consultation. After obtaining informed consent, a genderconcordant research assistant trained in qualitative interviewing techniques interviewed participants in a private setting in isiZulu or English. Interviews lasted approximately 30-90 minutes and were recorded, translated, and transcribed. Participants did not receive compensation for participation.

Transcripts were independently reviewed and coded, and resultant conceptual categories and emergent themes were discussed by the research team using content analysis [46, 47]. Several authors reviewed coding categories and emergent themes with the research assistants in order to explore additional themes and confirm accuracy of interpretation.

Ethics approvals were obtained from the McCord Hospital Research Ethics Committee (Durban, South Africa) and from the Partners Healthcare Institutional Review Board (Boston, USA). 


\section{Results}

3.1. Demographics. Baseline demographic data, HIV history, reported partner HIV status, and reproductive history for 30 female and 20 male participants are shown in Table 1. Women and men averaged 30 (SD 4) and 34 (SD 6) years of age, respectively, and had been diagnosed with HIV for a mean of 3 years (SD 2 women, SD 5 men). Seventy-three percent of women and $60 \%$ of men had completed secondary school, while $63 \%$ of women and $75 \%$ of men reported current employment. $73 \%$ of women were diagnosed with HIV prior to the referent pregnancy. Women had an average of 2 (SD 1) pregnancies (including current), 1.1 (SD 0.7) prior live births, 0.9 (SD 0.6) living children, and 18 (60\%) were pregnant at the time of interview. We have previously detailed the complexities of pregnancy intention in this sample, but about a third (11) of women described the referent pregnancy as explicitly planned [33]. Men had an average of 0.9 (SD 1) living children; three (16\%) reported partner pregnancy in the past year.

3.2. Overview. We have presented a conceptual framework for considering factors that impact periconception risk behavior [44]. Structural, individual, and dyadic domains affect access to risk reduction information (e.g., knowledge that ARVs can reduce sexual transmission risk), motivation (e.g., to adhere to prevention strategies), and ability to implement behavioral change (e.g., partnership dynamics and discussions of safer sex practices). Within this framework, HCWs have the potential to minimize risk behavior through providing HIV-affected couples with information about HIV transmission and conception, supporting disclosure, providing $\mathrm{ARV}$ s as prevention, and promoting adherence to HIV risk reduction strategies [44]. Here, we present data exploring participant experiences with reproductive counseling from HCWs. We present themes suggesting that, in this sample, HIV-infected men and women in serodiscordant partnerships (1) are aware of and receptive to the idea that one should speak to an HCW prior to becoming pregnant, (2) seldom seek or receive conception advice from healthcare workers, and (3) when advice is shared, patients receive a range of information around safer conception. In addition, (4) men are eager for safer conception advice.

3.2.1. Aware of and Open to Safer Conception and Pregnancy Information from HCWs. Most participants indicated that they had been informed by a HCW that they should seek advice when they were ready to conceive. In some cases, participants communicated that this advice might help minimize transmission to a child, and in some cases to a partner. This awareness was related to general information shared by counselors during routine ARV adherence training sessions (group adherence training sessions prior to ART initiation are routine in South Africa), regardless of the participant's fertility goals at the time.

They [healthcare workers during the training session] told me that when I have told her [disclosed to partner], we should come here [to the clinic] together so that they will explain to both of us. They tell us that we should come back with our partners so that the doctor tells us what to do in order for the virus not to be transferred to the child. (Participant B03, 26-year-old man)

They [counselors] said that we should come with our partners so that you explain to the doctor that you want to have a child so that he tells you what to do, and that was it. Did they say anything more? No, they only said that we should consult a doctor with your partner if you want to have children. (Participant B15, 29-year-old man)

In addition to knowing that they should tell a HCW if they wanted to have children, participants were open to seeking this advice from healthcare workers.

With us black people, if it happens that you get the virus and you die not having a child, your name just disappears and you are never mentioned. That would be difficult. So if it happens that you do get HIV then you should go to the clinic and talk to them [healthcare workers] so that they help you to get a child in a safe way. (Participant B04, 28-year-old man)

We want to have a child together because we love each other and we are so close to each other... I will probably go to special doctors when I am ready for that so that I hear from them what it is that I have to do in order to have a child since I have the virus and my partner does not. (Participant B16, 36-year-old man)

If you want to have children you need to consult the doctor... then they will advise you what to do. (Participant A27, 34-year-old woman)

3.2.2. Seldom Seek Safer Conception Information Prior to Conception. While most participants were aware that they should approach a healthcare worker prior to conception, few sought, or received safer conception advice. Participants described several barriers to accessing reproductive counseling prior to conception including fear of judgment from nurses and financial challenges.

They did not tell us that we should no longer have children, but you could see that is what they meant. The other day, one of the nurses made a comment and asked "why don't we go for family planning" because they do not want to see us coming back to take the treatment [ARVs for PMTCT] again. (Participant A26, 23-year-old woman)

I spoke to the doctor who said it is safe to have more children if I want to. He said I need to see 
TABLE 1: Study population characteristics.

\begin{tabular}{|c|c|c|}
\hline Characteristics & $\begin{array}{c}\text { Women } \\
n=30 \\
\text { mean } \pm \text { S.D. } \\
\text { number }(\%)\end{array}$ & $\begin{array}{c}\text { Men } \\
n=20 \\
\text { mean } \pm \text { S.D. } \\
\text { number }(\%)\end{array}$ \\
\hline Age (years) & $30 \pm 4$ & $34 \pm 6$ \\
\hline Completed matric or above ${ }^{\dagger}$ & $22(73 \%)$ & $12(60 \%)$ \\
\hline Employed & $19(63 \%)$ & $15(75 \%)$ \\
\hline Years since HIV diagnosis & $3 \pm 2$ & $3 \pm 5$ \\
\hline Currently on ART/ARVs & $21(70 \%)$ & $17 / 20(85 \%)$ \\
\hline HIV-negative (versus unknown status) partner ${ }^{\ddagger}$ & $14(46 \%)$ & $13(65 \%)$ \\
\hline Disclosed HIV status to partner* & $23(79 \%)$ & $15(78 \%)$ \\
\hline Pregnancy or partner pregnancy in the past year & $30(100 \%)$ & $3(16 \%)$ \\
\hline Pregnancy or partner pregnancy after HIV-diagnosis & $22(73 \%)$ & $2(11 \%)$ \\
\hline Pregnancies, including current & $2.1 \pm 1.1$ & - \\
\hline Live births & $1.1 \pm 0.7$ & - \\
\hline Currently living children & $0.9 \pm 0.6$ & $0.9 \pm 1.0$ \\
\hline
\end{tabular}

${ }^{\dagger}$ Completed final exams for high school (secondary school).

₹By participant report.

* Women-father of referent pregnancy. Men—current or most recent sexual partner.

him before I fall pregnant. He said I can come to him, but I didn't because he was expensive as he is a gynecologist. (Participant A13, 32-year-old woman)

Additional barriers may be related to dyadic factors. For example, participants described that they were told to seek reproductive counseling at the ARV clinic with their partners. However, about a third of participants had not disclosed his/her HIV status to their partner, making this scenario unlikely. Further, about a third of the women in this sample described the referent pregnancy as unplanned.

3.2.3. Range in Quality of Information Shared by Providers about Safer Conception in the Context of HIV Infection. Participants reported a range of information received from providers. At one end of the spectrum, some participants had not received advice about options for having children since their HIV diagnosis, including in the setting of expressing plans for having children.

They [healthcare workers] haven't advised me: they have asked me about it but they have never given me any advice. They asked me if I am planning on having more children and I told them, "Yes, I am planning on having one more." I have never received any advice. (Participant A28, 24year-old woman)

What advice have you received from health care workers... around having children after knowing your status? Except that I have to practice safe sex, there is nothing (Participant A30, 31-year-old woman)
Others had received helpful safer conception information from doctors or nurses at PMTCT, ARV, and gynecology clinics. Risk reduction strategies that participants had learned included artificial insemination, intercourse timed to peak fertility, manual insemination (for male-uninfected couples_the uninfected male ejaculates into a condom or other container and the semen is inserted into the woman's vaginal canal via a syringe or reversed condom), sperm washing, and intercourse with lubrication (to avoid abrasions).

They told me that I can go to one of those private hospitals to ask about sperm washing... One of the times when I came into the clinic there was a poster on the wall saying "if you want to have a child, speak to either a doctor or a nurse." So I asked the doctor, "do you think is it possible for me to have a child even if I'm positive?" But I had to go to one of those private hospitals to look into that thing [sperm washing]. (Participant B05, 31year-old man)

A doctor gave us a [syringe] which we had to use after sex to withdraw sperm [from the condom to insert into the woman].... We are both aware that I am positive and so we would use a condom all the time... and we received advice from the doctor on how to use the syringe that he gave us so that he [partner] does not get infected. (Participant A25, 32-year-old woman)

One participant suggested the importance of a lower plasma HIV viral load prior to conception, but it was not clear where she and her partner had learned this information. ART as prevention was not a component of the South African Department of Health Treatment Guidelines at the time of this study (or now) [48]. 
After finding out that my viral load was very low, even undetectable, he [husband] decided that let's take a chance and try and see what is going to happen. He said he has taken that decision, it's not that I am forcing him to take it. Then we just took a chance. (Participant A04, 28-year-old woman)

Some participants explained that the advice they had received about whether or not they, as HIV-infected individuals, could have children evolved over time-or varied with different providers.

So far they told me... that I cannot have children. But then they changed [and said] that I can have children, and that is what I am not sure of. (Participant B11, 33-year-old man)

3.2.4. Men Are Eager to Learn about Safer Conception. From our sample, many male participants had engaged with a HCW around discussions of safer conception or had sought out information from the internet, relatives, or other news sources.

\begin{abstract}
No [I have not had a conversation with a $\mathrm{HCW}$ ], but I've done research and they said that one can do artificial insemination but I am not sure if it is done on humans. ... Artificial insemination means that a person can be impregnated by a man, but... technology can be used to make a baby without them having sex... The child is yours because the semen is taken from you and can be injected into the women and a baby grows inside the woman, the genes of that child are yours. (Participant B13, 28-year-old man)
\end{abstract}

Several male participants became quite interested in safer conception options during the interview and planned to seek out additional advice from a HCW. One participant (B12, 35year-old man) responded to a question about fertility desire by saying, "so in the situation that I am in now I do not think I want to have children again," but by the end of the interview he asks:

Is it possible to have children if I am positive and my partner is negative?

Another participant initially stated, "I have two kids at the moment. Even before I was diagnosed [with HIV], we were not planning to have more... Two is enough." However, by the end of the interview, he asks:

I want to know if ... I decide to have kids how is that possible?... Maybe I'll try to find more ways to get information about how to have kids when you're HIV positive. (Participant B14, 39year-old man)

Women were not particularly eager for advice. However, this may simply reflect the study sample given that fewer women were planning a future pregnancy and many were still close to or in the midst of a current pregnancy.

\section{Discussion}

These qualitative data suggest that HIV-infected patients are increasingly aware of reproductive counseling opportunities. Many participants understood that HCWs may have valuable advice to offer to facilitate safer conception and were open to seeking this advice. While few participants had sought advice, some participants had received safer conception advice from healthcare encounters.

Prior studies suggest that the majority of HIV-infected patients are not receiving reproductive counseling and are reluctant to engage with healthcare workers to discuss reproductive plans $[12,35,36,39,49-51]$. Schwartz et al. [34, page 73] presented data collected during 2009 and reported that only $41 \%$ of HIV-infected women reported that an "ART healthcare provider had spoken with them about their options should they want to conceive in the future". In work by Cooper et al., collected in 2006, $19 \%$ of women and $6 \%$ of men had "consulted a doctor, nurse, or counselor in HIV care about fertility intentions" [38, page S44]. The fact that many participants, including men, in this small sample knew that HCWs may have advice to offer captures data not mentioned in prior studies. These data suggest that clinical settings may be adapting to accommodate the fertility goals of people living with HIV.

Many participants reported the expectation that they could access detailed counseling if they returned to the clinic when they were ready to have a child. From work by our group and others, several facts of periconception practice make this clinical approach precarious. Waiting to talk to a provider until one is ready to have a child eliminates the opportunity to discuss the risks of having children in order to inform the decision to have biologic children [24, 52, 53]. Many men and women living with HIV do not know their partner's status and/or have not disclosed to their partners. Prior to testing and disclosure, it is impossible for an individual or a couple to assess sexual transmission risk in the context of conception. Continued efforts to promote couple-based testing and supported disclosure are critical [54]. For those who decide to have children, a preconception conversation with a healthcare worker should include an assessment of the HIV-infected partner's health; the HIV status of the partner; if the woman is positive, a discussion of the risks of pregnancy when HIV infected; risks of transmission to a partner with various periconception risk reduction strategies; fertility assessment; the increased risk of transmission and acquisition during unprotected sex during pregnancy; the risks of perinatal transmission [44].

Furthermore, asking individuals or couples to return when they are ready to have children presupposes conception planning. However, many pregnancies are not explicitly planned $[55,56]$. Providing up-front information about the options for safer conception may communicate the importance of preconception planning - to protect the future child and the partner. Recent data from Johannesburg (South Africa) suggest high fertility intentions at ART initiation [34], reflecting the importance of providing safer conception information at treatment initiation and in followup. In addition, decisions about conception are often dyadic. A partner 
(who is not attending clinic) may make decisions about having children-if his or her partner has not been educated it is impossible for them to have an informed conversation about the risks and options for safer conception. In addition, life transitions may be quick and there may be plans for pregnancy long before a next visit with a provider [57].

Expecting a patient to raise the issue of fertility plans on his or her own may be problematic. While not a theme in our data, published data suggest that women and men living with HIV hesitate to reveal fertility plans to HCWs for fear of judgment $[36,58]$. It is not part of routine clinical practice to expect patients to tell providers when they are ready to discuss health behavior change (e.g., smoking, substance abuse, exercise, sexual behavior)-the onus is on the provider to actively inquire about behaviors that compromise health. Routine assessment of fertility goals and plans should be incorporated into clinical care for people living with HIV, with subsequent recommendations for safer conception or effective contraception options, depending on fertility goals. How to execute this in overburdened healthcare systems is a challenge but may require increased training in fertility intention assessment and comprehensive reproductive counseling for counselors.

Participants had learned of safer conception strategies from HCWs including artificial insemination, intercourse timed to peak fertility, sperm washing, home manual insemination, and intercourse with lubrication to avoid abrasions. The frequency with which sperm washing and artificial insemination was raised is interesting since these are some of the least accessible (geographically, economically) strategies for reducing transmission risk. Simpler risk reduction strategies such as delaying conception until the infected partner is on treatment with suppressed HIV RNA viral load, timing sex without condoms to peak fertility, circumcision for the male partner if he is uninfected, and manual insemination are likely to be more feasible. Our semistructured interview guide was not designed to probe specifically about particular techniques and it is possible that participants were more likely to recall discussions about and have faith in hightech concepts such as sperm washing compared to behavioral modifications such as timing unprotected sex to peak fertility. In addition, patients may have received limited information, perhaps due to insufficient clinician training on this topic. The WHO guidelines for serodiscordant couples offer some safer conception recommendations, in addition, a more comprehensive guideline was recently published by the Southern African HIV Clinicians Society and will be helpful for clinicians $[32,54]$. HCW training on the interpretation and application of these guidelines should be a priority for promoting comprehensive reproductive health counseling.

We found that, in this sample, male participants were eager to engage with HCWs in order to seek reproductive counseling. Prior data suggests that providers may have less insight into male reproductive intentions [31] and that men are less likely to seek advice from providers [38]. We previously published on the important role of men in conception decisions from an earlier analysis of these data [33], an observation which has been reported by others $[9,11,12,36,59-61]$. As reproductive counseling is integrated into HIV care, it will be crucial to increase male involvement. Interventions to engage men in contraception and family planning have been effective in several subSaharan African settings [61-63]. In addition, the dyadic nature of conception decisions and periconception risk behavior emphasizes the importance of a couple-oriented counseling approach when feasible [44].

The main limitations of the data are inherent to qualitative research-findings from this small qualitative sample are meant to generate hypotheses to pursue in future larger scale research. In addition, our participants were attending clinical services at a semiprivate hospital and may not represent the broader population who access public sector care or those who do not access any healthcare. While this clinic does not have a formal program for safer conception counseling, several of the authors previously worked at this clinic which may have heightened some of the clinic providers' awareness around reproductive counseling for people living with HIV. Finally, patient perspectives of past experiences with provider counseling may not accurately reflect what occurred; provider perspectives are also needed to understand current practices.

\section{Conclusion}

These are the first data to explore patient experiences with provider provision of reproductive counseling in KwaZulu Natal, where $41 \%$ of women attending antenatal clinics are HIV infected [45]. This work suggests that men and women living with HIV are aware that safer conception options may be available and are interested in accessing this information. Further, there is a clear need to expand the quality and reach of periconception risk reduction information to both providers and patients. These data serve as important hypothesis generation to guide future research as reproductive counseling interventions are developed.

\section{Acknowledgments}

The authors would like to thank study participants for their participation and our research assistants for their work on this project. L. T. Matthews received funding support from the American Society of Tropical Medicine and Hygiene/Burroughs-Wellcome Fund Postdoctoral Fellowship in Tropical Infectious Diseases, the Mark and Lisa Schwartz Family Foundation, and a K23 award (NIMH MH095655). D. R. Bangsberg was supported by the Mark and Lisa Schwartz Family Foundation and by a K24 award (NIMH MH087227).

\section{References}

[1] J. L. Chen, K. A. Phillips, D. E. Kanouse, R. L. Collins, and A. Miu, "Fertility desires and intentions of HIV-positive men and women," Perspectives on Sexual and Reproductive Health, vol. 33, no. 4, pp. 144-165, 2001.

[2] L. C. G. Frodsham, F. Boag, S. Barton, and C. Gilling-Smith, "Human immunodeficiency virus infection and fertility care 
in the United Kingdom: demand and supply," Fertility and Sterility, vol. 85, no. 2, pp. 285-289, 2006.

[3] L. Panozzo, M. Battegay, A. Friedl et al., "High risk behaviour and fertility desires among heterosexual HIV-positive patients with a serodiscordant partner-two challenging issues," Swiss Medical Weekly, vol. 133, no. 7-8, pp. 124-127, 2003.

[4] I. Heard, R. Sitta, F. Lert et al., "Reproductive choice in men and women living with HIV: evidence from a large representative sample of outpatients attending French hospitals (ANRSEN12-VESPA study)," AIDS, vol. 21, supplement 1, pp. S77S82, 2007.

[5] L. Myer, C. Morroni, and K. Rebe, "Prevalence and determinants of fertility intentions of HIV-infected women and men receiving antiretroviral therapy in South Africa," AIDS Patient Care and STDs, vol. 21, no. 4, pp. 278-285, 2007.

[6] S. G. Brubaker, E. A. Bukusi, J. Odoyo, J. Achando, A. Okumu, and C. R. Cohen, "Pregnancy and HIV transmission among HIV-discordant couples in a clinical trial in Kisumu, Kenya," HIV Medicine, vol. 12, no. 5, pp. 316-321, 2011.

[7] A. Kaida, I. Andia, M. Maier et al., "The potential impact of antiretroviral therapy on fertility in sub-Saharan Africa," Current HIV/AIDS Reports, vol. 3, no. 4, pp. 187-194, 2006.

[8] M. Maier, I. Andia, N. Emenyonu et al., "Antiretroviral therapy is associated with increased fertility desire, but not pregnancy or live birth, among HIV+ women in an early HIV treatment program in rural Uganda," AIDS and Behavior, vol. 13, no. 1, pp. S28-S37, 2009.

[9] J. Beyeza-Kashesya, A. M. Ekstrom, F. Kaharuza, F. Mirembe, S. Neema, and A. Kulane, "My partner wants a child: a crosssectional study of the determinants of the desire for children among mutually disclosed sero-discordant couples receiving care in Uganda," BMC Public Health, vol. 10, article 247, 2010.

[10] J. Homsy, R. Bunnell, D. Moore et al., "Reproductive intentions and outcomes among women on antiretroviral therapy in rural Uganda: a prospective cohort study," PLOS ONE, vol. 4, no. 1, Article ID e4149, 2009.

[11] S. Nakayiwa, B. Abang, L. Packel et al., "Desire for children and pregnancy risk behavior among HIV-infected men and women in Uganda," AIDS and Behavior, vol. 10, supplement 1, pp. S95-S104, 2006.

[12] O. Awiti Ujiji, A. M. Ekström, F. Ilako, D. Indalo, and B. Rubenson, "I will not let my HIV status stand in the way.' Decisions on motherhood among women on ART in a slum in Kenya- a qualitative study," BMC Women's Health, vol. 10, article 13, 2010.

[13] B. Auvert, D. Taljaard, E. Lagarde, J. Sobngwi-Tambekou, R. Sitta, and A. Puren, "Randomized, controlled intervention trial of male circumcision for reduction of HIV infection risk: the ANRS 1265 trial," PLoS Medicine, vol. 2, no. 11, article e298, 2005.

[14] R. C. Bailey, S. Moses, C. B. Parker et al., "Male circumcision for HIV prevention in young men in Kisumu, Kenya: a randomised controlled trial," The Lancet, vol. 369, no. 9562, pp. 643-656, 2007.

[15] R. H. Gray, G. Kigozi, D. Serwadda et al., "Male circumcision for HIV prevention in men in Rakai, Uganda: a randomised trial," The Lancet, vol. 369, no. 9562, pp. 657-666, 2007.

[16] M. S. Cohen, Y. Q. Chen, M. McCauley et al., "Prevention of HIV-1 infection with early antiretroviral therapy," The New England Journal of Medicine, vol. 365, no. 6, pp. 493-505, 2011.

[17] D. Donnell, J. M. Baeten, J. Kiarie et al., "Heterosexual HIV1 transmission after initiation of antiretroviral therapy: a prospective cohort analysis," The Lancet, vol. 375, no. 9731, pp. 2092-2098, 2010.
[18] S. Attia, M. Egger, M. Müller, M. Zwahlen, and N. Low, "Sexual transmission of HIV according to viral load and antiretroviral therapy: systematic review and meta-analysis," AIDS, vol. 23, no. 11, pp. 1397-1404, 2009.

[19] Q. A. Karim, S. S. A. Karim, J. A. Frohlich et al., "Effectiveness and safety of tenofovir gel, an antiretroviral microbicide, for the prevention of HIV infection in women," Science, vol. 329, no. 5996, pp. 1168-1174, 2010.

[20] R. M. Grant, J. R. Lama, P. L. Anderson et al., "Preexposure chemoprophylaxis for HIV prevention in men who have sex with men," The New England Journal of Medicine, vol. 363, no. 27, pp. 2587-2599, 2010.

[21] J. M. Baeten, D. Donnell, P. Ndase et al., "ARV PrEP for HIV-1 prevention among hetersexual men and women," in Proceedings of the 19th Conference on Retroviruses and Opportunistic Infections (CROI'12), Washington, Seattle, USA, 2012.

[22] M. C. Thigpen, P. M. Kebaabetswe, D.K. Smith et al., "Daily oral antiretroviral use for the prevention of HIV infection in heterosexually active young adults in Botswana: results from the TDF2 study," in Proceedings of the 6th IAS International AIDS Society Conference on HIV Pathogenesis, Treatment and Prevention, Rome, Italy, 2011.

[23] P. Barreiro, J. A. Castilla, P. Labarga, and V. Soriano, "Is natural conception a valid option for HIV-serodiscordant couples?" Human Reproduction, vol. 22, no. 9, pp. 2353-2358, 2007.

[24] L. T. Matthews and J. S. Mukherjee, "Strategies for harm reduction among HIV-affected couples who want to conceive," AIDS and Behavior, vol. 13, supplement 1, pp. S5-S11, 2009.

[25] L. T. Matthews, J. M. Baeten, C. Celum, and D. R. Bangsberg, "Periconception pre-exposure prophylaxis to prevent HIV transmission: benefits, risks, and challenges to implementation," AIDS, vol. 24, no. 13, pp. 1975-1982, 2010.

[26] M. A. Lampe, D. K. Smith, G. J. E. Anderson, A. E. Edwards, and S. R. Nesheim, "Achieving safe conception in HIVdiscordant couples: the potential role of oral preexposure prophylaxis (PrEP) in the United States," American Journal of Obstetrics and Gynecology, vol. 204, no. 6, pp. 488.e1-488.e8, 2011.

[27] P. L. Vernazza, I. Graf, U. Sonnenberg-Schwan, M. Geit, and A. Meurer, "Pre-exposure prophylaxis and timed intercourse for HIV-discordant couples willing to conceive a child," AIDS, vol. 25, no. 16, pp. 2005-2008, 2011.

[28] CDC, "Recommendations for assisting in the prevention of perinatal transmission of human T-lymphotropic virus type III/lymphadenopathy-associated virus and acquired immunodeficiency syndrome," MMWR, vol. 34, no. 48, pp. 721-726, 731.

[29] Ethics Committee of the American Society for Reproductive Medicine, "Special considerations regarding human immunodeficiency virus and assisted reproductive technologies," Fertility and Sterility, vol. 62, Supplement 1, p. 85S, 1994.

[30] CDC, "Revised guidelines for HIV counseling, testing, and referral," MMWR, vol. 50, no. 19, pp. 1-57, 2001.

[31] J. Harries, D. Cooper, L. Myer, H. Bracken, V. Zweigenthal, and P. Orner, "Policy maker and health care provider perspectives on reproductive decision-making amongst HIV-infected individuals in South Africa," BMC Public Health, vol. 7, article 282, 2007.

[32] L. G. Bekker, V. Black, L. Myer et al., "Guideline on safer conception in fertile HIV-infected individuals and couples," Southern African Journal of HIV Medicine, no. 40, pp. 31-44, 2011. 
[33] L. T. Matthews, T. Crankshaw, J. Giddy et al., "Decisionmaking and periconception practices among HIV-positive men and women attending HIV services in Durban, South Africa," AIDS and Behavior. In press.

[34] S. R. Schwartz, S. H. Mehta, T. E. Taha, H. V. Rees, F. Venter, and V. Black, "High pregnancy intentions and missed opportunities for patient-provider communication about fertility in a South African cohort of HIV-positive women on antiretroviral therapy," AIDS and Behavior, vol. 16, no. 1, pp. 69-78, 2011.

[35] S. Finocchario-Kessler, J. K. Dariotis, M. D. Sweat et al., "Do HIV-infected women want to discuss reproductive plans with providers, and are those conversations occurring?" AIDS Patient Care and STDs, vol. 24, no. 5, pp. 317-323, 2010.

[36] D. Cooper, J. Harries, L. Myer, P. Orner, and H. Bracken, “'Life is still going on': reproductive intentions among HIV-positive women and men in South Africa," Social Science and Medicine, vol. 65, no. 2, pp. 274-283, 2007.

[37] M. L. Gogna, M. M. Pecheny, I. Ibarlucía, H. Manzelli, and S. B. López, "The reproductive needs and rights of people living with HIV in Argentina: health service users' and providers' perspectives," Social Science and Medicine, vol. 69, no. 6, pp. 813-820, 2009.

[38] D. Cooper, J. Moodley, V. Zweigenthal, L. G. Bekker, I. Shah, and L. Myer, "Fertility intentions and reproductive health care needs of people living with HIV in Cape Town, South Africa: implications for integrating reproductive health and HIV Care services," AIDS and Behavior, vol. 13, supplement 1, pp. S38S46, 2009.

[39] V. Paiva, E. Ventura Filipe, N. Santos, T. Novaes Lima, and A. Segurado, "The right to love: the desire for parenthood among men living with HIV," Reproductive Health Matters, vol. 11, no. 22, pp. 91-100, 2003.

[40] L. Myer, K. Rebe, and C. Morroni, "Missed opportunities to address reproductive health care needs among HIVinfected women in antiretroviral therapy programmes," Tropical Medicine and International Health, vol. 12, no. 12, pp. 1484-1489, 2007.

[41] M. B. Laws, Y. S. Bradshaw, S. A. Safren et al., "Discussion of sexual risk behavior in HIV care is infrequent and appears ineffectual: a mixed methods study," AIDS and Behavior, vol. 15, no. 4, pp. 812-822, 2011.

[42] C. Sprague, M. F. Chersich, and V. Black, "Health system weaknesses constrain access to PMTCT and maternal HIV services in South Africa: a qualitative enquiry," AIDS Research and Therapy, vol. 8, article 10, 2011.

[43] H. van Rooyen, K. Durrheim, and G. Lindegger, "Advicegiving difficulties in voluntary counselling and testing: a distinctly moral activity," AIDS Care, vol. 23, no. 3, pp. 281286, 2011.

[44] T. Crankshaw, L. T. Matthews, J. Giddy et al., "A conceptual framework for periconception HIV transmission risk reduction among HIV serodiscordant couples," Reproductive Health Matters. In press.

[45] National Department of Health, South Africa, National Antenatal Sentinel HIV and Syphilis Prevalence Survey in South Africa, National Department of Health, Pretoria, South Africa, 2010.

[46] A. Strauss and J. M. Corbin, Basics of Qualitative Research: Techniques and Procedures for Developing Grounded Theory, Sage, Thousand Oaks, Calif, USA, 1998.
[47] P. R. Ulin, E. T. Robinson, and E. E. Tolley, Qualitative Methods in Public Health: A Field Guide For Applied Research, JolleyBass, San Francisco, Calif, USA, 2005.

[48] National Department of Health, South Africa, Clinical guidelines for the managment of HIV \& AIDS in adults and adolescents, 2010.

[49] A. Kaida, F. Laher, S. A. Strathdee et al., "Childbearing intentions of HIV-positive women of reproductive age in Soweto, South Africa: the influence of expanding access to haart in an hiv hyperendemic setting," American Journal of Public Health, vol. 101, no. 2, pp. 350-358, 2011.

[50] P. Orner, D. Cooper, L. Myer, V. Zweigenthal, L. G. Bekker, and J. Moodley, "Clients' perspectives on HIV/AIDS care and treatment and reproductive health services in South Africa," AIDS Care, vol. 20, no. 10, pp. 1217-1223, 2008.

[51] D. McCarraher, C. Cuthbertson, D. Kung'U, C. Otterness, L. Johnson, and G. Magiri, "Sexual behavior, fertility desires and unmet need for family planning among home-based care clients and caregivers in Kenya," AIDS Care, vol. 20, no. 9, pp. 1057-1065, 2008.

[52] P. Barreiro, J. Del Romero, M. Leal et al., "Natural pregnancies in HIV-serodiscordant couples receiving successful antiretroviral therapy," Journal of Acquired Immune Deficiency Syndromes, vol. 43, no. 3, pp. 324-326, 2006.

[53] R. J. Chadwick, J. E. Mantell, J. Moodley, J. Harries, V. Zweigenthal, and D. Cooper, "Safer conception interventions for HIV-affected couples: implications for resourceconstrained settings," Topics in Antiviral Medicine, vol. 19, no. 4, pp. 148-155, 2011.

[54] Wold Health Organization, Guidance on Couples HIV Testing and Counselling Including Antiretroviral Therapy For Treatment and Prevention in Serodiscordant Couples, World Health Organization, Geneva, Switzerland, 2012.

[55] C. MacPhail, A. E. Pettifor, S. Pascoe, and H. V. Rees, "Contraception use and pregnancy among 15-24 year old South African women: a nationally representative crosssectional survey," BMC Medicine, vol. 5, article 31, 2007.

[56] Department of Health South Africa, Medical Research Council, and OrcMacro, South Africa Demographic and Health Survey 2003, Department of Health, Pretoria, South Africa, 2007.

[57] A. Harrison and L. F. O'Sullivan, "In the absence of marriage: long-term concurrent partnerships, pregnancy, and HIV risk dynamics among South African young adults," AIDS and Behavior, vol. 14, no. 5, pp. 991-1000, 2010.

[58] G. Wagner, S. Linnemayr, C. Kityo, and P. Mugyenyi, "Factors associated with intention to conceive and its communication to providers among HIV clients in Uganda," Maternal and Child Health Journal, pp. 1-9, 2011.

[59] S. Yeatman, "HIV infection and fertility preferences in rural Malawi," Studies in Family Planning, vol. 40, no. 4, pp. 261276, 2009.

[60] D. J. Smith and B. C. Mbakwem, "Life projects and therapeutic itineraries: marriage, fertility, and antiretroviral therapy in Nigeria," AIDS, vol. 21, supplement 5, pp. S37-S41, 2007.

[61] UNDP/UNFPA/WHO/ World Bank Special Programme of Research, Development and Research Training in Human Reproduction, "Programming for male involvement in reproductive health," Report of the Meeting of WHO Regional Advisors in Reproductive Health WHO/PAHO, WHO, Washington, DC, USA, 2001.

[62] D. Shattuck, B. Kerner, K. Gilles, M. Hartmann, T. Ng'ombe, and G. Guest, "Encouraging contraceptive uptake by motivating men to communicate about family planning: the Malawi 
Male Motivator project," American Journal of Public Health, vol. 101, no. 6, pp. 1089-1095, 2011.

[63] A. Terefe and C. P. Larson, "Modern contraception use in Ethiopia: does involving husbands make a difference?" American Journal of Public Health, vol. 83, no. 11, pp. 15671571, 1993. 


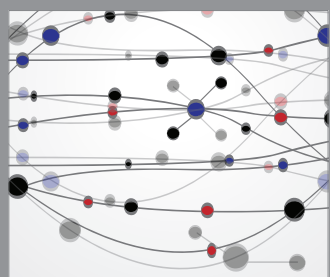

The Scientific World Journal
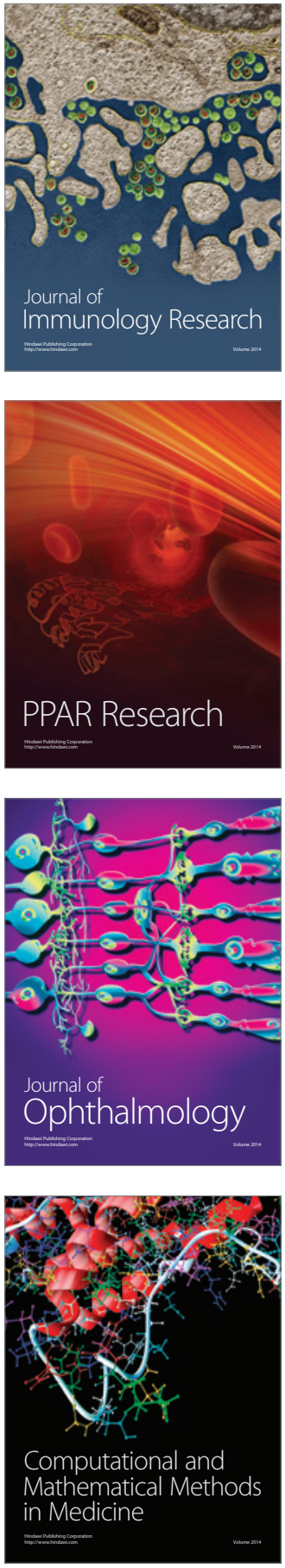

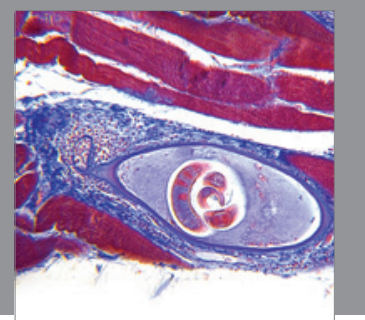

Gastroenterology

Research and Practice
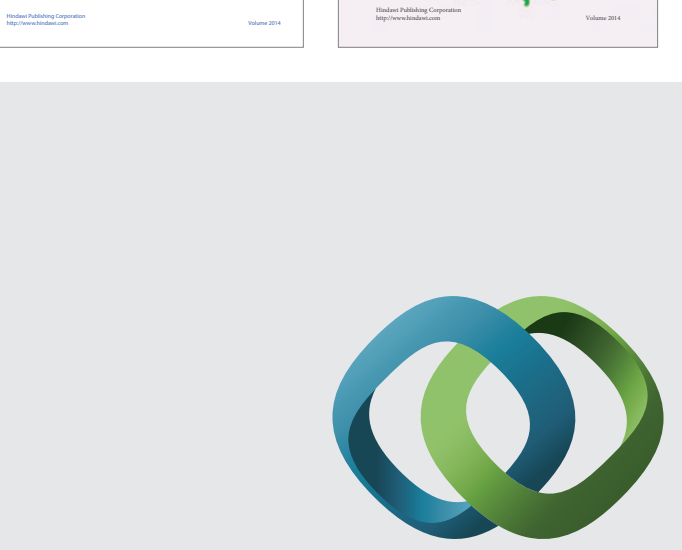

\section{Hindawi}

Submit your manuscripts at

http://www.hindawi.com
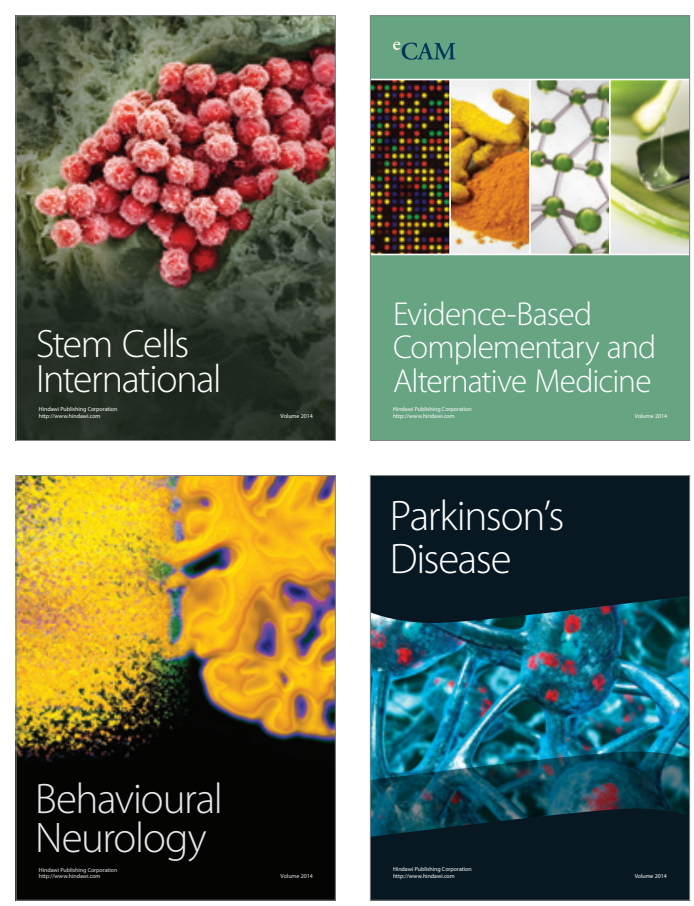

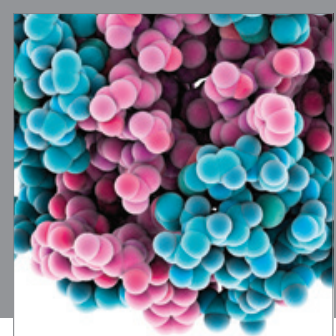

Journal of
Diabetes Research

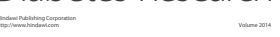

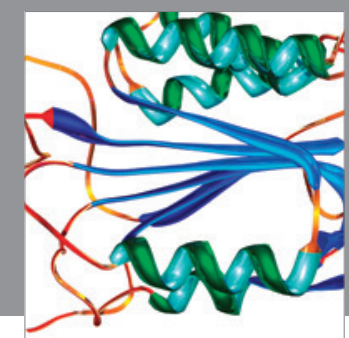

Disease Markers
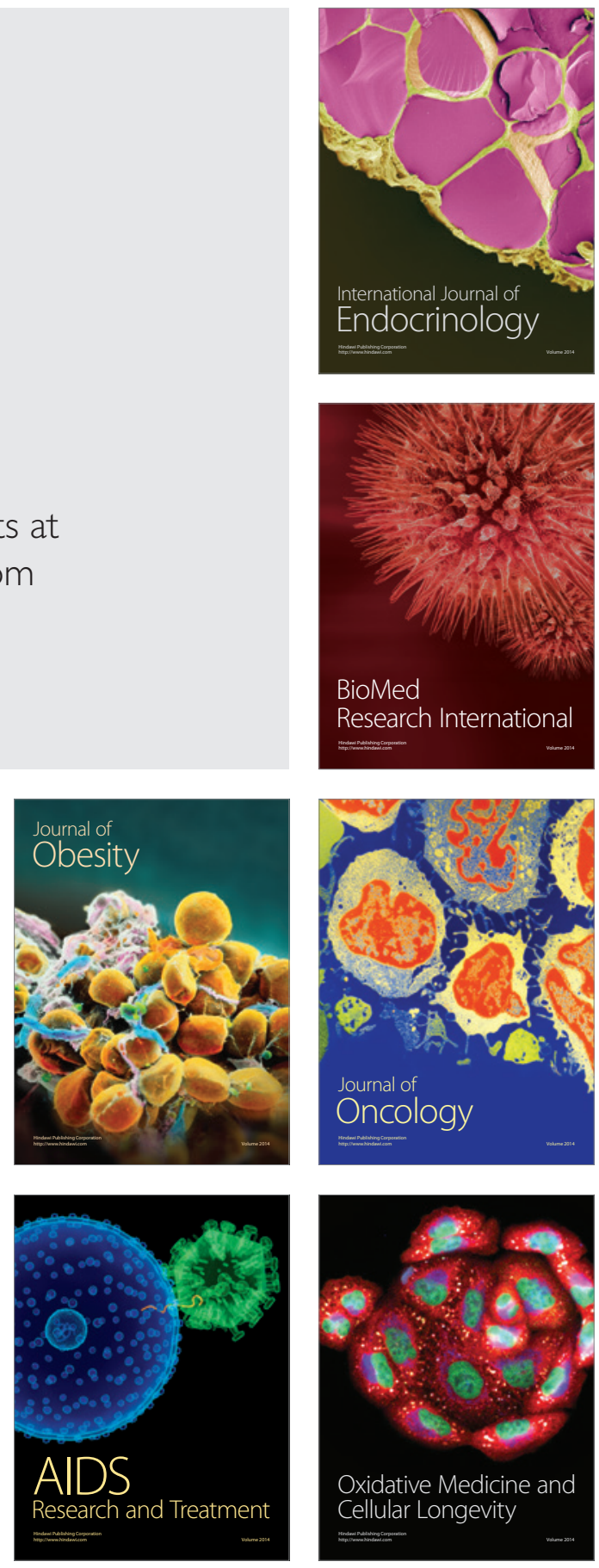